\title{
Retrograde mastoidectomy with canal wall reconstruction with bone graft in acquired cholesteatoma
}

\author{
Yasser Shewel $^{1^{*} \text { (D) and Ahmed Abougabal }}{ }^{2}$
}

\begin{abstract}
Background: This study aimed to report the surgical outcomes of retrograde mastoidectomy with canal wall reconstruction using a bone graft that secured in place using glass ionomer cement $(\mathrm{GlC})$ in adult patients with acquired cholesteatoma.

Results: This study was conducted on 50 adult patients with acquired cholesteatoma who underwent retrograde mastoidectomy with a reconstruction of canal wall using a bone graft from the mastoid cortex. The preoperative and postoperative audiological evaluation was done; in addition, non-echoplanar (EPI) diffusion-weighted MRI was obtained at least 1 year postoperatively to detect recidivism of cholesteatoma.

Recidivism of cholesteatoma was observed in 4/50 ears (8\%) using diffusion-weighted MRI and confirmed during revision mastoidectomy. The audiological assessment showed a marked and statistically significant improvement of preoperative $A B G$ from 30 to $21 \mathrm{~dB}$ in addition to the improvement of preoperative $A C$ from 42 to $33 \mathrm{~dB}$. ABG of $20 \mathrm{~dB}$ or less was achieved in 50\% of the ears. No reaction occurred to GIC in all the ears.

Conclusions: Retrograde mastoidectomy with canal wall reconstruction with bone graft was associated with a low rate of recidivism and significant improvement of the hearing. GIC is safe and effective in stabilization of bone graft in canal wall reconstruction.
\end{abstract}

Keywords: Cholesteatoma, Recidivism, GlC, Mastoidectomy, Reconstruction

\section{Background}

Controversy exists in the literature regarding the management of cholesteatoma for many decades. The focus of this debate is whether to perform open or closed techniques $[1,2]$.

Canal wall down (CWD) mastoidectomy has been performed since the end of the nineteenth century. This procedure entails the exenteration of the mastoid air cells with the removal of the posterior wall of the external canal. The main advantage of canal wall down mastoidectomy is adequate exposure of hidden spots in

\footnotetext{
* Correspondence: yshwel@yahoo.com

'Department of Otolaryngology, Faculty of Medicine, Alexandria University, Champollion Street, El-Khartoum Square, El Azarita Medical Campus, Alexandria, Egypt

Full list of author information is available at the end of the article
}

retrotympanum and anterior tympanic space and, therefore, reduces the incidence of residual cholesteatoma. However, this technique is associated with an unacceptable incidence of recurrent ear infection, shallow middle ear with the poorer hearing outcome, vertigo, and wide unpleasant meatoplasty [3].

Canal wall up mastoidectomy (CWU) was advocated by Antoni Candela in 1954 and described by Klaus Jansen in 1958 to overcome the previous drawbacks of open mastoidectomy, yet the closed technique is associated with a high rate of recidivism. Preserving the posterior canal wall avoids open cavity problems although it hampers proper visualization of hidden areas that are adequately exposed by open technique. Therefore, otologists concluded that preserving the posterior meatal wall increases the

\section{Springer Open}

(๑) The Author(s). 2020 Open Access This article is licensed under a Creative Commons Attribution 4.0 International License, which permits use, sharing, adaptation, distribution and reproduction in any medium or format, as long as you give appropriate credit to the original author(s) and the source, provide a link to the Creative Commons licence, and indicate if changes were made. The images or other third party material in this article are included in the article's Creative Commons licence, unless indicated otherwise in a credit line to the material. If material is not included in the article's Creative Commons licence and your intended use is not permitted by statutory regulation or exceeds the permitted use, you will need to obtain permission directly from the copyright holder. To view a copy of this licence, visit http://creativecommons.org/licenses/by/4.0/. 
recidivism while its removal is associated with cavity problems $[2,3]$.

Many modifications were advocated to avoid the disadvantages of both techniques including restoration of the posterior canal wall with cartilage, bone grafts, implants like titanium plate, obliteration techniques or recently, using the endoscope, either as an assistant tool to the microscope or exclusively to eradicate cholesteatoma $[1,2,4-8]$.

One of criticizing point of obliteration of the mastoid cavity and reconstructive techniques for canal wall is that they may hide recidivism of cholesteatoma with a subsequent serious complication. However, non-EPI diffusion-weighted magnetic resonance imaging (DWI or DW-MRI) has solved this issue as it is the imaging modality of choice for postoperative follow-up of patients with cholesteatoma. It has high diagnostic accuracy in the detection of recidivism, and its utility can avoid unnecessary revision mastoidectomy [9-15].

The aim of this study was to report the surgical outcomes of retrograde mastoidectomy with canal wall reconstruction using a bone graft from the mastoid cortex that secured in place using GIC in adult patients with acquired cholesteatoma.

In addition, we assessed the effectiveness and safety of glass ionomer cement GIC in the stabilization of mastoid cortical bone graft in canal wall reconstruction.

\section{Methods}

This study was conducted on 50 adult patients with acquired cholesteatoma who underwent retrograde mastoidectomy with a reconstruction of canal wall using a bone graft from the mastoid cortex at the Department of Otolaryngology-Head Neck Surgery from January 2015 to 2019. The ethical committee in our University approved this study.

All patients were subjected preoperatively to complete history taking, otoscopic examination, audiological evaluation, and radiological assessment.

Evaluation of hearing was done preoperatively by measuring the pure tone air conduction (PTA-AC), bone conduction (PTA-BC) thresholds, and air-bone gap (PTA-ABG) at $0.5,1.2$, and $3 \mathrm{kHz}$.

Radiological assessment was done by $0.5 \mathrm{~mm}$ cuts high-resolution computerized tomography of petrous bone to determine the extent of cholesteatoma.

\section{Surgical technique}

The mastoid was approached by postauricular incision, and $\mathrm{T}$-shaped musculoperiosteal (Palva) flap was created and dissected posteroinferiorly. The temporalis muscle was identified and retracted superiorly for proper exposure of McEwen's triangle and mastoid process. The temporalis fascia graft was harvested, and adequate bone graft was harvested from the mastoid cortex using a chisel and hammer.

Elevation of tympanomeatal flap was done from inferior to superior direction, and the tympanic membrane retracted inferiorly.

Drilling started from inside the external auditory from 1 toward 10 o'clock in the right ear and from lateral to medial till, and the neck of the cholesteatoma sac was identified. Atticoantrotomy was performed, and the sac was followed posteriorly by progressive drilling without disruption of cholesteatoma sac until healthy air cell was encountered behind the sac sacrificing only the upper third of the canal wall to facilitate the further reconstruction.

The neck of malleus was cut using nipper forceps, and the head of malleus and incus were removed for full exposure of cholesteatoma sac which dissected from the mastoid cavity in posterior to anterior direction reaching to the neck of cholesteatoma and resected from the healthy tympanic membrane.

The cortical bone was fashioned to fit the defect of the superior wall of the external auditory canal, and two grooves were drilled using $1 \mathrm{~mm}$ diamond burr superiorly at tegmen tympani and inferiorly at lower canal wall to fix bone graft in the appropriate location (Fig. 1). The graft was secured into the appropriate position using dental GIC (Fig. 2) (Ketac-Cem, Espe Dental AG, Seefeld, Germany).

Tympanic membrane defect was reconstructed by temporalis fascia which covered also the area of canal wall reconstruction. Ossicular reconstruction was made by interposition techniques between the tympanic membrane and head of a stapes using either autogenous incus or head of the malleus. In case of erosion of stapes superstructure, reconstruction was done using whole Teflon TORP between the tympanic membrane and footplate of the stapes.

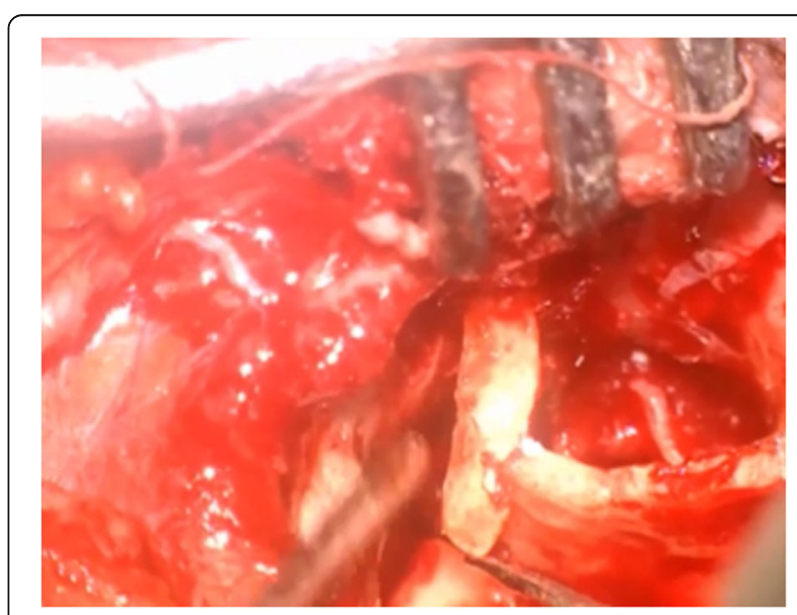

Fig. 1 Reconstruction of the canal wall with bone graft 


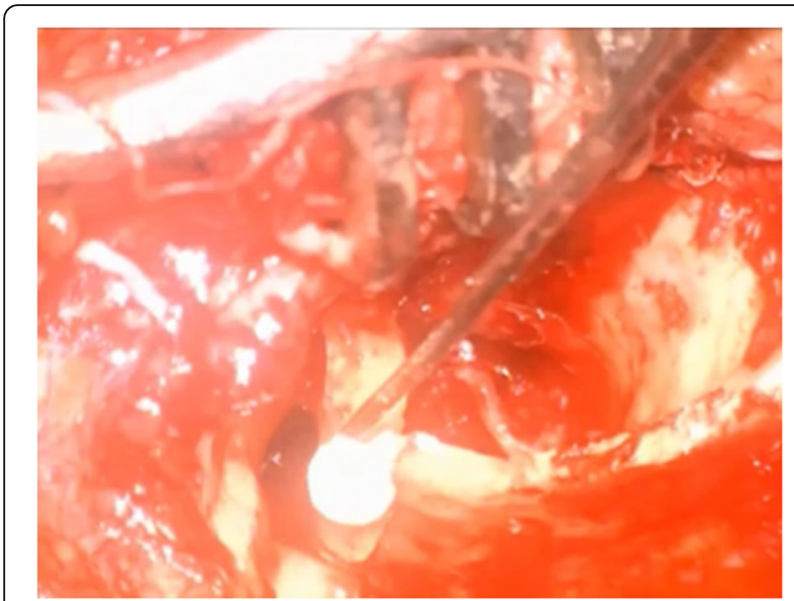

Fig. 2 Glass ionomer cement $(\mathrm{G} \mid \mathrm{C})$ used for stabilization of bone graft

The posterosuperior half of the tympanic membrane is augmented by a piece of tragal cartilage to prevent postoperative retraction.

Any defects in canal reconstruction were filled by small pieces of cartilage and attic completely obliterated with pieces of cartilage for augmenting the canal wall reconstruction. The mastoid cavity was obliterated by temporalis muscle flap superiorly and by musculoperiosteal flap inferiorly to give additional support to canal wall reconstruction.

\section{Follow-up}

The patients were followed up for at least 1 year. The surgical outcomes were documented with special emphasis on cholesteatoma recidivism, granulation tissue formation, or foreign body reaction, the integrity of the graft, dryness of the ear, and postoperative hearing results.

Postoperative hearing was assessed at 6th month and last follow-up visit by air conduction (PTA-AC), bone conduction (PTA-BC) thresholds, and air-bone gap (PTA-ABG) at $0.5,1.2$, and $3 \mathrm{kHz}$.

Non-EPI diffusion-weighted MRI was obtained at least 1 year postoperatively to detect recidivism of cholesteatoma. For the analysis of DWI, the radiologist looked for hyperintense lesions on high $b$-values (800 or $1000 \mathrm{~s} / \mathrm{mm}^{2}$ ).

All statistical analysis was calculated using GraphPad Prism program, version 5 for Windows (GraphPad Software, San Diego, CA, USA). A comparison between preoperative and postoperative hearing results was done using the $t$-test. $P<.05$ was considered statistically significant.

\section{Results}

\section{Patient characteristics}

Fifty adult patients with acquired cholesteatoma were included in this research. The age of patients ranged from
18 to 55 years with an average of $36.3 \pm 11.27$ years at the time of mastoidectomy. There were 33 male $(66 \%)$ and 17 female (34\%) patients. The average follow-up after surgery ranged from 1 up to 4 years with a mean duration of 2.8 years.

\section{Intraoperative findings}

All cholesteatomas were located in the attic and extend to the mastoid antrum.

Erosion of malleus, incus, and stapes was occurred in $10 / 50$ ears (20\%), 50/50 ears (100\%), and 18/50 ears (36\%), respectively.

\section{Audiometric findings}

There was a significant improvement of mean preoperative PTA-AC from $42 \pm 5.3$ to $33 \pm 5.6 \mathrm{~dB}$ postoperatively $(P<0.0001)$.

The preoperative PTA-ABG was $30 \pm 5.4 \mathrm{~dB}$ while it was $21 \pm 6.4 \mathrm{~dB}$ postoperatively, and this change was statistically significant $(P<0.0001)$.

No statistically significant difference was found between the preoperative and postoperative PTA BC $(11.60 \pm 2.9$ dBversus $12.13 \pm 2.6 \mathrm{~dB})$.

Ossicular reconstruction was performed with interposition technique from the head of stapes to tympanic membrane using the incus or head of malleus in 32 ears. These showed an average preoperative PTA-ABG of 30 $\pm 5 \mathrm{~dB}$ and an average postoperative value of $20 \pm 5.8 \mathrm{~dB}$ demonstrating significant improvement $(P<0.0001)$.

TORP was used in 18 ears, which had an average preoperative PTA-ABG of $31 \pm 6.2 \mathrm{~dB}$, with the postoperative value of $24 \pm 6.8 \mathrm{~dB}(P<0.0001)$. The changes between the preoperative and postoperative PTA-ABG values were statistically significant in both techniques of ossicular reconstruction.

The preoperative and postoperative ABG in $10 \mathrm{~dB}$ interval was shown in Table 1 . Out of 32 ears that underwent interposition technique, only one ear (3.1\%) showed a postoperative $A B G$ of $0-10 \mathrm{~dB}$, and 17 ears (53.12\%) showed a postoperative ABG of $10-20 \mathrm{~dB}$. A postoperative $\mathrm{ABG}$ of $20-30 \mathrm{~dB}$ was detected in 11 ears (34.37\%), and a value $>30 \mathrm{~dB}$ was observed in 3 ears (9.37\%).

Table 1 Preoperative and postoperative ABG in $10 \mathrm{~dB}$ interval

\begin{tabular}{|c|c|c|c|c|}
\hline \multirow[t]{3}{*}{ PTA ABG } & \multicolumn{2}{|c|}{$\begin{array}{l}\text { Interposition technique ( } 32 \\
\text { ears) }\end{array}$} & \multicolumn{2}{|c|}{ TORP (18 ears) } \\
\hline & \multicolumn{2}{|l|}{ Number (\%) } & \multicolumn{2}{|l|}{ Number (\%) } \\
\hline & Preoperative & Postoperative & Preoperative & Postoperative \\
\hline $0-10 \mathrm{~dB}$ & 0 & $1(03.10)$ & 0 & 0 \\
\hline $11-20 \mathrm{~dB}$ & $1(03.10)$ & 17 (53.12) & 0 & 7 (38.88) \\
\hline $21-30 \mathrm{~dB}$ & $18(56.25)$ & $11(34.37)$ & $10(55.55)$ & 7 (38.88) \\
\hline$>30 \mathrm{~dB}$ & $13(40.62)$ & $3(9.37)$ & $8(44.44)$ & $4(22.22)$ \\
\hline
\end{tabular}


Regarding TORP reconstruction, no patient showed improvement of postoperative ABG to $0-10 \mathrm{~dB}$. ABG of $10-20 \mathrm{~dB}$ was observed in 7 ears $(38.88 \%)$ and between 20 and $30 \mathrm{~dB}$ in another 7 ears $(38.88 \%)$. The postoperative $\mathrm{ABG}$ was more than $30 \mathrm{~dB}$ in 4 ears $(22.22 \%)$.

\section{Cholesteatoma recidivism}

Non-EPI diffusion-weighted MRI showed recidivism of cholesteatoma in 4/50 ears (8\%), and this recidivism was confirmed during revision surgery. Recidivism located in the attic in one ear and atticoantral region in 3 ears. Two out four of ears with recidivism showed necrosis of bone graft (Fig. 3).

\section{Dryness of ear}

Dryness of ear was achieved in 45/50 ears (90\%) while recurrent ear discharge occurred in 5/50 ears (10\%) including 4 ears with recidivism of cholesteatoma in addition to one ear with residual perforation. CWD mastoidectomy was undergone in patients with cholesteatoma recidivism.

\section{Integrity of tympanic membrane}

Residual perforation of the tympanic membrane was seen in only one ear $(2 \%)$ that underwent tympanoplasty.

\section{Reaction to glass ionomer cement (GIC)}

No reaction or granulation was seen secondary to using glass ionomer cement (GIC).

\section{Discussion}

Eradication of cholesteatoma, prevention of recurrence, and restoration of hearing are the ideal goals of mastoid surgery. However, the main two surgical procedure canal

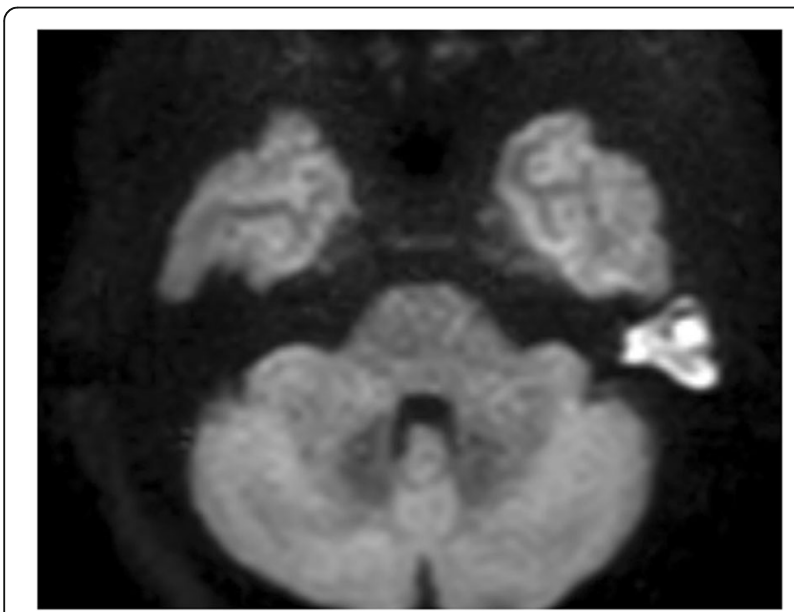

Fig. 3 Diffusion-weighted MRI ( $b=800 \mathrm{~s} / \mathrm{mmsq}$ ) showing recurrent left cholesteatoma exhibiting bright signal within the left middle ear cavity denoting diffusion restriction walls up and down mastoidectomy cannot achieve these goals $[3,16-21]$.

The removal of the canal wall grants improved and direct visualization of the whole epitympanum and posterior tympanum [22]. Wüllstein understood this concept when he described his technique of canal wall reconstruction with osteoplastic flap surgery in 1974 [6]. Portmann used a bone graft from mastoid or the posterior meatal wall itself for canal wall reconstruction $[3,5]$. Others have modified this technique by using a microplate for fixation of the reconstruction [23]. Feldmann used the microsurgical saw for removal of the posterior canal wall in 1978 and reimplant it again for the reconstruction of the canal wall [24].

The major issues of reconstruction of the canal wall with graft are proper fitting, stabilization, and necrosis of bone graft.

In this study, mastoidectomy was done in a retrograde manner (inside-outside technique) producing a small cavity by avoiding unnecessary drilling of healthy bone.

Reconstruction of the canal wall was done using bone graft harvested from the mastoid cortex before doing mastoidectomy. Fitting and fixation of bone graft were challenging. We resolved this issue by stabilization of mastoid bone graft using GIC that harden within a few minutes after its application.

GIC was developed since the 1970s. It is commonly used in otology since 1989 in bringing incudostapedial defect, fixation of the casings and electrodes of cochlear implant, and fixation of the stapes prosthesis at the long process of incus during stapedectomy [25].

To our knowledge, this is the first time to use GIC for fixation of bone graft for canal wall reconstruct in mastoidectomy. No patient had foreign body reaction or extrusion throughout follow-up.

Regarding the late necrosis of bone graft, we augmented the canal wall reconstruction by using small pieces of cartilage to support the attic, and mastoid was obliterated by temporalis muscle and musculoperiosteal flap, and this can explain the low incidence of bone graft necrosis that was occurred in only two ears (4\%).

Mercke perform CWD mastoidectomy and used Feldmann's micro saw to harvest meatal wall that reinserted after cholesteatoma removal and obliterated the mastoid with bone chips and muscle flap and reported that residual cholesteatoma was found in 3/57 ears, and dryness of ears was achieved in 56/57 [26].

Recent meta-analysis studies reported a higher incidence of cholesteatoma recurrence in CWU versus CWD mastoidectomy [27, 28]. Timolin et al. reported that recurrence ranged from 9 to $70 \%$ (average 30\%) in CWU mastoidectomy, while it was between 5 and 17\% (average 8.5\%) in CWD mastoidectomy [28]. 
In this study, recidivism of cholesteatoma was observed in 4/50 ears (8\%) using diffusion-weighted MRI and confirmed during second look mastoidectomy. Therefore, the low rate of recidivism in our study demonstrated that removal of canal wall for exenteration of cholesteatoma that was followed by its reconstruction with a bone graft can achieve a lower recurrence rate that is comparable to canal wall down mastoidectomy.

Walker et al. performed mastoidectomy with canal wall reconstruction and reported recidivism of cholesteatoma in (34/253) $13 \%$ of ears during second-look ossiculoplasty, and the preoperative ABG improved from 27.8 $\mathrm{dB}$ preoperatively to $23.4 \mathrm{~dB}$ postoperatively [29].

Kronenberg et al. removed the posterior canal wall during mastoidectomy to allow for removal of cholesteatoma and reimplanted the canal wall again. The authors detected recurrent cholesteatoma in $6 / 49$ patients (12\%), and this recurrence was recognized in all ears by nonEPI diffusion-weighted MRI [30].

Midline search was done by Harris et al. about the reconstruction of the posterior canal wall with or without mastoid obliteration and reported a recidivism rate of $5.3-20 \%$. They concluded that reconstruction of the posterior canal wall and/or mastoid obliteration may better alternative to CWU and CWD mastoidectomy as this technique is associated with lower recidivism and reduced postoperative otorrhea [31].

Harris et al. showed that the incidence of ear discharge was higher in CWD mastoidectomy (27\%) compared to CWU mastoidectomy (3.3\%) while it occurred in $9.7 \%$ of ears with the reconstruction of the meatal wall [31]. In our study, only 5 ears (10\%) had ear discharge due to recidivism of cholesteatoma in 4 ears and residual perforation in one ear.

Harris et al. showed that in group with CWU mastoidectomy, the average pre- and postoperative hearing loss was $32 \mathrm{~dB}$ and $20 \mathrm{~dB}$, respectively, while in CWD mastoidectomy the average pre- and postoperative hearing loss was $35.6 \mathrm{~dB}$ and $30 \mathrm{~dB}$, respectively, while in group with canal wall reconstruction, the average pre- and postoperative hearing loss was $30.6 \mathrm{~dB}$ and $22 \mathrm{~dB}$, respectively [31].

The hearing outcome of our patients seems comparable with those reported by other studies on cholesteatoma surgery with canal wall reconstruction; postoperative measurements showed a marked and statistically significant improvement of preoperative $A B G$ from 30 to $21 \mathrm{~dB}$ in addition to the improvement of preoperative $\mathrm{AC}$ from 42 to $33 \mathrm{~dB}$. ABG of $20 \mathrm{~dB}$ or less was achieved in $50 \%$ of ears.

Several variables influence the hearing results after cholesteatoma surgery including the condition of mucosa and weather healthy or edematous, depth of the middle ear, ventilation of middle ear, presence of stapes superstructure, surgical technique, and type of prosthesis [32]. In this technique in our study, we had good middle ear depth for proper ossiculoplasty that performed for all patients in the primary surgery with significant postoperative hearing improvement.

One of the most critical factors that had a great influence of ossiculoplasty and postoperative hearing results was whether or not the stapes suprastructure was intact. It was reported that an intact e stapes suprastructure is essential for the stable and adequate ossicular reconstruction and good hearing outcome [33], and this was compatible with the results of this study as interposition technique between head of stapes and tympanic membrane gave better hearing results and more incidence of ABG of $20 \mathrm{~dB}$ or less compared to TORP $(56 \%$ versus $38 \%)$.

\section{Conclusion}

Retrograde mastoidectomy with canal wall reconstruction with bone graft combines the advantages of canal wall up and down mastoidectomy and associated with a low rate of recidivism and significant improvement of the hearing.

Glass ionomer cement (GIC) was used safely for fixation of bone graft in place during canal wall reconstruction with no adverse reaction.

\section{Abbreviations \\ EPI: Echoplanar; GIC: Glass ionomer cement; CWU: Canal wall up; CWD: Canal wall down; TORP: Total ossicular replacement prothesis}

\section{Acknowledgements}

Not applicable

\section{Consent to participate}

Informed written consent obtained from all participants.

\section{Authors' contributions}

YS: Contributions to the conception, design of the work; the acquisition, analysis, interpretation of data; drafted the work, revised it, approved the submitted version, and agreed both to be personally accountable for the author's own contributions and to ensure that questions related to the accuracy or integrity of any part of the work, even ones in which the author was not personally involved, are appropriately investigated, resolved, and the resolution documented in the literature. AA: Contributions to the Conception, interpretation of data; revised it substantively revised it and approved the submitted version and agreed both to be personally accountable for the author's own contributions and to ensure that questions related to the accuracy or integrity of any part of the work, even ones in which the author was not personally involved, are appropriately investigated, resolved, and the resolution documented in the literature. All authors read and approved the final manuscript.

\section{Funding}

None

\section{Availability of data and materials}

The datasets used and/or analyzed during the current study are available from the corresponding author on reasonable request.

Ethics approval and consent to participate

The ethical committee of faculty of medicine, Alexandria University, Egypt, approved this work and informed written consent obtained from all participants (Ethical number 00007645). 


\section{Consent for publication}

Not applicable

\section{Competing interests}

The authors declare that they have no competing interests.

\section{Author details}

'Department of Otolaryngology, Faculty of Medicine, Alexandria University, Champollion Street, El-Khartoum Square, El Azarita Medical Campus, Alexandria, Egypt. ${ }^{2}$ Faculty of Medicine, Alexandria University, Alexandria, Egypt.

Received: 12 March 2020 Accepted: 14 May 2020

Published online: 02 July 2020

\section{References}

1. Dornhoffer UL (2004) Retrograde mastoidectomy with canal wall reconstruction: a follow-up report. Otol Neurotol 25(5):653-660. https://doi. org/10.1097/00129492-200409000-00002

2. Roth TN, Haeusler R (2009) Inside-out technique cholesteatoma surgery: a retrospective long-term analysis of 604 operated ears between 1992 and 2006. Otol Neurotol 30(1):59-63. https://doi.org/10.1097/mao. 0b013e31818ee0a7

3. Portmann M (1971) The problem of the cavity in tympanoplastic surgery. Laryngoscope 81(8):1233-1241. https://doi.org/10.1288/00005537197108000-00006

4. Minovi A, Venjacob J, Volkenstein S, Dornhoffer J, Dazert S (2014) Functional results after cholesteatoma surgery in an adult population using the retrograde mastoidectomy technique. Eur Arch Otorhinolaryngol 271(3): 495-501. https://doi.org/10.1007/s00405-013-2452-x

5. Portmann M, Hiranandani N (1970) Functional results in the reconstruction of bony meatus after radical mastoid operation. Laryngoscope 80(1):105110. https://doi.org/10.1288/00005537-197001000-00008

6. Wullstein SR (1974) Osteoplastic epitympanotomy. Ann Otol Rhinol Laryngol 83(5):663-669. https://doi.org/10.1177/000348947408300515

7. Deveze A, Rameh C, Puchol MS, Lafont B, Lavieille JP, Magnan J (2010) Rehabilitation of canal wall down mastoidectomy using a titanium ear canal implant. Otol Neurotol 31(2):220-224. https://doi.org/10.1097/MAO. Ob013e3181c9960d

8. Presutti L, Gioacchini FM, Alicandri-Ciufelli M, Villari D, Marchioni D (2014) Results of endoscopic middle ear surgery for cholesteatoma treatment: a systematic review. Acta Otorhinolaryngol Ital 34(3):153-157

9. Sharifian $H$, Taheri E, Borghei P, Shakiba M, Jalali AH, Roshanfekr M, Firouznia K (2012) Diagnostic accuracy of non-echo-planar diffusion-weighted MRI versus other MRI sequences in cholesteatoma. J Med Imaging Radiat Oncol 56(4):398-408. https://doi.org/10.1111/j.1754-9485.2012.02377.x

10. Garrido L, Cenjor C, Montoya J, Alonso A, Granell J, Gutierrez-Fonseca R (2015) Diagnostic capacity of non-echo planar diffusion-weighted MRI in the detection of primary and recurrent cholesteatoma. Acta otorrinolaringologica espanola 66(4):199-204. https://doi.org/10.1016/j.otorri. 2014.07.006

11. Edfeldt L, Stromback K, Danckwardt-Lilliestrom N, Rask-Andersen H, Abdsaleh S, Wikstrom J (2013) Non-echo planar diffusion-weighted MRI increases follow-up accuracy after one-step step canal wall-down obliteration surgery for cholesteatoma. Acta Otolaryngol 133(6):574-583. https://doi.org/10.3109/00016489.2012.762118

12. von Kalle T, Amrhein P, Koitschev A (2015) Non-echoplanar diffusionweighted MRI in children and adolescents with cholesteatoma: reliability and pitfalls in comparison to middle ear surgery. Pediatr Radiol 45(7):10311038. https://doi.org/10.1007/s00247-015-3287-y

13. Patel $B$, Hall A, Lingam $R$, Singh A (2018) Using non-echoplanar diffusion weighted MRI in detecting cholesteatoma following canal wall down mastoidectomy - our experience with 20 patient episodes. J Int Adv Otol 14(2):263-266. https://doi.org/10.5152/iao.2018.5033

14. Delrue S, De Foer B, van Dinther J, Zarowski A, Bernaerts A, Vanspauwen R, Casselman JW, Offeciers E, Somers T (2019) The value of diffusion-weighted MRI in the long-term follow-up after subtotal petrosectomy for extensive cholesteatoma and chronic suppurative otitis media. Otol Neurotol 40(1): e25-e31. https://doi.org/10.1097/MAO.0000000000002049

15. Stasolla A, Magliulo G, Lo Mele L, Prossomariti G, Luppi G, Marini M (2004) Value of echo-planar diffusion-weighted MRI in the detection of secondary and postoperative relapsing/residual cholesteatoma. La Radiologia medica 107(5-6):556-568

16. Whittemore KR Jr, Merchant SN, Rosowski JJ (1998) Acoustic mechanisms: canal wall-up versus canal wall-down mastoidectomy. Otolaryngol Head Neck Surg 118(6):751-761. https://doi.org/10.1016/S0194-5998(98)70264-5

17. Uzun C, Kutoglu T (2007) Assessment of visualization of structures in the middle ear via Tos modified canal wall-up mastoidectomy versus classic canal wall-up and canal wall-down mastoidectomies. Int J Pediatr Otorhinolaryngol 71(6):851-856. https://doi.org/10.1016/j.jporl.2007.02.004

18. Wilkie MD, Chudek D, Webb CJ, Panarese A, Banhegyi G (2019) Canal wall down mastoidectomy with obliteration versus canal wall up mastoidectomy in primary cholesteatoma surgery. J Laryngol Otol:1-5. https://doi.org/10. 1017/S0022215119002408

19. Dutta M (2018) Canal wall up versus canal wall down mastoidectomy: considerations for the new-age otologists. J Int Adv Otol 14(3):506-508. https://doi.org/10.5152/iao.2018.5413

20. Cook JA, Krishnan S, Fagan PA (1996) Hearing results following modified radical versus canal-up mastoidectomy. Ann Otol Rhinol Laryngol 105(5): 379-383. https://doi.org/10.1177/000348949610500510

21. Hulka GF, McElveen JT Jr (1998) A randomized, blinded study of canal wall up versus canal wall down mastoidectomy determining the differences in viewing middle ear anatomy and pathology. Am j Otol 19(5):574-578

22. Alves RD, Cabral Junior F, Fonseca AC, Bento RF (2016) Mastoid obliteration with autologous bone in mastoidectomy canal wall down surgery: a literature overview. Int Arch Otorhinolaryngol 20(1):76-83. https://doi.org/10 1055/s-0035-1563382

23. Àwengen DF PMRifit, removal of the posterior external ear canal wall. In Sanna M e, International CaMSPotF, Conference on Cholesteatoma and Mastoid Surgery, Alghero-Sardinia IRCEI, 1997:588-94.

24. Feldmann H (1978) Osteoplastic approach in chronic otitis media by means of a microsurgical reciprocating saw. Clin Otolaryngol Allied Sci 3(4):515520. https://doi.org/10.1111/j.1365-2273.1978.tb00744.x

25. Righini-Grunder F, Hausler R, Chongvisal S, Caversaccio M (2015) Glass ionomer cement in otological microsurgery: experience over 16 years. Eur Arch Otorhinolaryngol 272(10):2749-2754. https://doi.org/10.1007/s00405014-3276-z

26. Mercke U (1987) The cholesteatomatous ear one year after surgery with obliteration technique. Am J Otol 8(6):534-536

27. Kerckhoffs KG, Kommer MB, van Strien TH, Visscher SJ, Bruijnzeel H, Smit AL, Grolman W (2016) The disease recurrence rate after the canal wall up or canal wall down technique in adults. Laryngoscope 126(4):980-987. https:// doi.org/10.1002/lary.25591

28. Tomlin J, Chang D, McCutcheon B, Harris J (2013) Surgical technique and recurrence in cholesteatoma: a meta-analysis. Audiol Neurootol 18(3):135142. https://doi.org/10.1159/000346140

29. Walker PC, Mowry SE, Hansen MR, Gantz BJ (2014) Long-term results of canal wall reconstruction tympanomastoidectomy. Otol Neurotol 35(6):954-960

30. Kronenberg J, Shapira Y, Migirov L (2012) Mastoidectomy reconstruction of the posterior wall and obliteration (MAPRO): preliminary results. Acta Otolaryngol 132(4):400-403. https://doi.org/10.3109/00016489.2011.643456

31. Harris AT, Mettias B, Lesser TH (2016) Pooled analysis of the evidence for open cavity, combined approach and reconstruction of the mastoid cavity in primary cholesteatoma surgery. J Laryngol Otol 130(3):235-241. https:// doi.org/10.1017/S0022215116000013

32. Neudert M, Zahnert T, Lasurashvili N, Bornitz M, Lavcheva Z, Offergeld C (2009) Partial ossicular reconstruction: comparison of three different prostheses in clinical and experimental studies. Otol Neurotol 30(3):332-338. https://doi.org/10.1097/MAO.0b013e31819679dd

33. Chang CC, Chen MK (2000) Canal-wall-down tympanoplasty with mastoidectomy for advanced cholesteatoma. J Otolaryngol 29(5):270-273

\section{Publisher's Note}

Springer Nature remains neutral with regard to jurisdictional claims in published maps and institutional affiliations. 